\title{
Hypermnesia and Amnesia: Remembering (with) the Body and Post-Conflict Memorials and Architectures ${ }^{1}$
}

\author{
Andrea Borsari ${ }^{1}$, Giovanni Leoni ${ }^{1}$ \\ 1 University of Bologna, Bologna, Italy \\ Corresponding author: Giovanni Leoni (giovanni.leoni@unibo.it)
}

Published 12 January 2022

\begin{abstract}
The article consists of two parts. The first part (§§ 1-2) investigates the indiscriminate and absolute remembering and forgetting of everything, hypermnesia and amnesia as the extreme terms that research has used and uses for the different phenomena of memory, both in individuals and in social and political forms. In the face of these shifts it is thus indispensable to re-establish a critique of the paradoxical effects of memory aids and, at the same time, to seek new forms of remembrance that by mixing an experiential dimension and public sphere refocus the attention on the connection between latency, tension and experiential triggers of involuntary memory and on the ability to break through the fictions of collective memory. On this basis, the second part of the article ( $\S 3-4)$ analyses how the experience of political and racial deportation during World War II drastically changed the idea of memorial architecture. More specifically, the analysis deals with a kind of memorial device that must represent and memorialise persons whose bodies have been deliberately cancelled. The aim is to present and analyse the artistic and architectonic efforts to refer to those forgotten bodies, on the one hand, and on the other hand to point out how for these new kind of memorials the body of the visitor is asked to participate, both physically and emotionally, in this somehow paradoxical search for lost bodies, offering oneself as a substitute.
\end{abstract}

\section{Key Words}

Body, experience, memorial aids, memorial architecture, remembering and forgetting.

\section{Introduction:}

\section{The insurmountable tension between remembering and forgetting}

The indiscriminate and absolute remembering and forgetting of everything, hypermnesia and amnesia, are the extreme terms that research has used and uses for the different phenomena of remembrance, both in individuals and in social and political forms. With its shifts and oscillations, the tension between remembering and forgetting within these extremes has marked the research in this field of study, as well as the policies that interact with it. Indeed, a recent trend has been to consider the results of neuroscientific studies on the functioning of individual memory and the role of forgetting for its physiology as an invitation to sever the internal link between ethics and memory. Faced with these shifts it becomes essential to explore the different possibilities of reintroducing an experiential and bodily dimension into the public memorial sphere by focusing attention on the connection between latency, tension and experiential triggers that stimulate all senses. It is a matter of seeing how to reactivate the forms of involuntary remembering, even reawakening dormant memories, and tearing down the fictions of collective remembrance. Thus proposing to keep alive the tension between what is worthy of being remembered and the unforgettable and developing it as a living phenomenon.

Summing up the epochal turning point in the public policies and practices of memory produced with the end

The first part (§§ 1-2) is by Andrea Borsari, the second part $(\S \S 3-4)$ is by Giovanni Leoni. 
of the Cold War and with the bustling start of the renewed processes of globalisation, in his agile Libro della memoria e della speranza [Book of Memory and Hope] Remo Bodei questioned the relationship between historical remembrance, forgetting and collective identity (Bodei 1995). In fact, in this context the philosopher focused on the character of unresolved and continuous tension between contrasting elements that defines the core of the problem in which the "contradictory and divided will" of "remembering beyond all disruptions" and the "forgetting of a lost past" are opposed, interpreting this tension as "tension incessantly reproduced between continuity and discontinuity". Faced with the risk of favouring "the role of forgetting" due to the excess of self-defence against the extremists of memory, an imbalance towards the side of forgetting must be avoided. Though memory, while never safe, "will struggle tenaciously to not always be defeated". In fact, factors that contribute to the changing and forgetting of the past include the loss of "institutional support" and "social frameworks of remembrance" that reinforced it, the presence of an "infinitely pliable past that does not pass", the choice that is made with respect to it "based on a present where it never intermingles in its entirety", the investment that is not only "cognitive" but also "emotional" that is incessantly required, its constant characteristic of "controversial and contentious ground" and, no less significant, its characteristic of "place of paradoxical alliances between remembering and forgetting". Hence the need to adopt a posture that mixes the "logic of forgetting" and the "logic of remembering", giving rise to a "conflicting complicity between remembering and forgetting" that works by virtue of the schema nec tecum nec sine te (neither with you nor without you). As much as they are in perennial conflict, "forgetting is as indispensable to remembering as remembering is to forgetting" (Bodei 1995).

In recent years, however, there has been a trend to consider the results of neuroscientific studies on the functioning of individual memory - equivocating the different layers of discourse - as an invitation to sever the internal link between ethics and remembrance, starting from the assumption related to memory according to which remembering and forgetting are human faculties, neither good nor bad. For example, in her 2016 book on the forms of forgetting, Aleida Assmann exhorts studies on remembrance to focus on forgetting and its forms (Assmann 2016). Her considerations are based on the question posed by Jan Philipp Reemtsma: "Remembering is an obligation, the semantics of remembrance are imperative. But what is positive about remembering? Remembering and forgetting are human faculties, neither good nor bad, because they both help deal with life" (Reemtsma 2010). Such a position is read as an explicit correction to the central meaning assumed by the culture of remembering in Germany, in parallel with the conviction that the historical weight of the holocaust cannot be eliminated by forgetting about it. Hence a point of view develops that reveals itself as being problematic in ambiguously promoting constructive and therapeutic forgetting with respect to a traumatic past and in the failure to distinguish between the selective character of individual remembering and forgetting as a means to compose divided societies. The recognition of the seven ways to forget leads to the emergence of a "paradigm shift that has to do with a global ethic". However, this shift confirms "the oldest self-description of human memory, valid both for individuals and for societies and cultures". That is, most memory is lost, and remembering is always limited "because it refers to the experience of an individual or group" (Assmann 2016). This resembles more a sort of immutable law of memory than an authorisation to make its processes available to any manipulation of cultural practices of forgetting or to identify constructivist criteria for the art of forgetting.

Faced with such a scenario, for a position that intends to maintain the conflicting tension between remembering and forgetting in changed circumstances without reducing itself to "the ecology of forgetting" (Cimatti 2020), it seems necessary to question and stimulate the strategies of remembering that work on latency and experiential triggering - starting from contact but which engage all senses - of the involuntary memory that incorporates the past into the present and of the "unforgettable" that "always newly disrupts the fictions of collective memory" (Agamben 2005). The close link between the immemorial and the unforgettable is shown - as Agamben himself made clear in his "idea of the immemorial" - in involuntary memory. In it, memory, "which gives us back the forgotten thing, is itself each time forgotten and this forgetfulness is its light": "It is not what we have lived and then forgotten that now returns imperfectly to consciousness, but rather, at that point, we access what never was, forgetfulness as the home of consciousness. [..] The immemorial, which plunges from memory to memory without ever coming to memory itself, is properly unforgettable" (Agamben 2020).

Some possible directions for this research include three perspectives that diverge from the unilateral results of excessive remembering, the hypermnesia that crowds memories and, by hardening them, makes them indiscernible, and of excessive forgetting, the amnesia that reacts to an excess of voluntary remembering but ends up confusing the physiological processing of forgetting with the questioning of immovable history underpinned by the ethical link with memory. The three examples given below as a first draft are those of providing spatial experience through the building of places having a strategy of reawakening "dormant memories", the conflicting relationship between monuments as aids to memory and counter-monuments as attempts to escape the paradoxical erasure of memory induced by the former, and finally of the recovery of a perspective derived from Georges Perec's infra-ordinary to experience crucial places of remembrance where time and human destruction have left nothing but pale traces of the horror that took place in them, as in the exemplary case of Auschwitz Birkenau. 


\section{Three strategies: dormant memories, experiential monuments and gaze at ground level}

In his work of self-fiction focused on the search for his lost youth in Paris and the elaboration of an "art of memory with which he has evoked the most ungraspable human destinies and uncovered the life-world of the occupation", as stated in the reason for his Nobel Prize for Literature (Le Monde 2014), the French writer Patrick Modiano showed how "the topography of a city becomes your whole life called to mind": "The city - as it happens Paris, the city of my birth - is linked to my very first childhood impressions, and these impressions were so strong that I have been constantly exploring the "mysteries of Paris' ever since. When I was about nine or ten, it came about that I was out walking alone, and even though I was scared of getting lost, I went further and further into neighbourhoods I was unfamiliar with on the right bank of the Seine. That was in daylight, which reassured me. At the start of adolescence I worked hard to overcome my fear and venture out at night even further afield by Métro. That is how you get to know about the city, and I was following the example of most of the novelists I admired and for which, since the $19^{\text {th }}$ century, the city - call it Paris, London, Saint Petersburg or Stockholm - was the backdrop and one of the main themes of their books" (Modiano 2014). Correcting his consecration as the "Proust of our time", Modiano clarified: "Today, I get the sense that memory is much less sure of itself, and that the search for lost time collides with a "mass of forgetting that obscures everything"', clarifying that, lacking the ability to recreate the past in its smallest details, he intends more modestly "to make a few faded words visible again, like lost icebergs adrift on the surface of the ocean" (Modiano 2014). The method according to which he implements his own specific version of the Proustian procedure of recovering involuntary memory is that of recovering "souvenirs dormants" through the present experience of Parisian topography that produces a hybrid between past and present, reactivating its potential for the future, as is clear from his subsequent exemplary novel Sleep of Memory whose title refers precisely to "dormant memories" (Modiano 2017). In it, the city is "littered with ghosts, as numerous as metro stations and all the dots that light up when you press the buttons on the electric route map", feeling a nostalgia for the impossibility of "reliv[ing] something we'd already experienced, in the same time, the same place, and the same circumstances, but liv[ing] it much better than the first time, without the mistakes, hitches, and idle moments". So his personal lesser version of time would proceed through an attempt to organise his memories, putting them together like largely isolated puzzle pieces, thanks to which, "as we fumble through these efforts, certain names light up intermittently, like signals that might lead to a hidden path". The narrator thus tries to get to the bottom of the list of places and names, feeling like "an amnesiac, trying to break through a layer of ice and forgetfulness". To the point of evoking the dissolution of the self in the figure - derived from Blanqui's Eternity by the Stars - of the multiplication of lookalikes and the possible pluralisation of memories: "Thousands and thousands of doubles of yourself follow the thousands of paths that you didn't take at various crossroads in your life, because you thought there was but a single one" (Modiano 2017).

In the discussion on the opportunity and purpose of memorial monuments such as buildings and physical objects, the consideration of the paradoxical nature of the monument has assumed an increasingly important role, like all mnestic aids (hypomnemata) - since Plato's Phaedrus - starting with writing: when we take note of something, we can afford to forget it because the device takes on the responsibility of remembering it for us. The monument "suffers from the same disease: created to remind us, it ends up making us forget, being both a machine of remembrance and forgetting", or as Robert Musil recalls: "The remarkable thing about monuments is that one does not notice them. There is nothing in this world as invisible as a monument" (Pinotti 2014). The commemorative monument belongs to the broader class of external reminders, for which each memory relegated to an external device assigned the task of preserving it is exposed to the risk of being forgotten, since this same act of assignment concurrently implies the dispensation, the exoneration from remembering personally, and therefore an implicit authorisation to forget. If this is the structural link that is established between voluntary monuments and memory, in recent decades a broad strategy has been employed to ensure that memorials avoid the fate of being immediately transformed into devices of forgetting, to the contrary becoming capable of preserving and handing down memories. Among the ways to overcome this perverse effect of remembering, Pinotti himself has identified some countermonumental strategies such as: highlighting the absence and emptiness in place of what has been destroyed (the Twin Towers, the Buddha of Bamyan); insisting on verticality but denying it meaning and mirroring it underground (Jochen and Esther Shalev-Gerz: Harburger Mahnmal gegen Faschis$m u s)$; subtract from the vision to combat opacity due to habit, so that I notice something only when its presence, although in principle visible, is denied to me (Christo and Jean Claude, wrapping or packaging); change from noble, resilient materials (stone, marble, metal) to lighter materials or non-materials like air and light (Shiro Takahashi, inflatable Buddha; Hiro Yamagata, laser images); apparently mimic a traditional monument, but depriving it of meaning, including through abstraction (the stelae of Richard Serra, the intransitive monuments of Cattelan) (Pinotti 2014). Other cases could be added to this type, such as miniaturisation (the small bronze chairs in front of the places of welcome, where the young Jews had been saved, planned for the design competition for the Villa Emma Memorial in Nonantola) or the joint presence of the separate elements of the information centre and the 
stelae in the Denkmal für die ermordeten Juden Europas by Peter Eisenmann: "In the memorial these two heterogeneous dimensions of remembrance are topographically differentiated. Above ground the absolutely illegible stelae, below them an information centre reserved for reading. The immaterial threshold that separates these two forms of memory is the true place of the memorial. Keeping them separate is so important because otherwise the guilty conscience, which wants nothing more than to forget, would cover that which must remain unforgettable with a flood of memories" (Agamben 2005).

What emerges is a more determined propensity to emphasise the fleeting, transient and ephemeral character of the act and the memorial object that turns into an increasingly specific experience, not a pre-ordained experience but an action that depends on the involvement and active intervention of those who carry it out, well exemplified by the motto of the work of the Gerz spouses on "producing a monument together" (ein Denkmal zum Mitmachen): "Because nothing in the long term can withstand injustice in our place" (Harburger Mahnmal 1994). And the reflection of Georges Didi-Huberman on the possibility of experiencing the central place of the Shoah, the Auschwitz Birkenau camp, speaks precisely to an experiential conception focused on the involvement of the body (Didi-Huberman 2011, 2013). These are physical places where unspeakable things happened, but where at the same time there is (almost) nothing left to recall these events. Faced with the progressive inability to feel due to overexposure, the possibility of restoring a sense of these places, retracing the path of "places despite everything", is implemented through the choice to lower the gaze to the ground, to suspend the ideas received and to reconstruct circumscribed, partial images capable of commemorating the defeats of history and reactivating the image of what has been in the present, with a reference first only alluded to and then explicit in the infra-ordinary elaborated by Georges Perec, in the tension between metropolitan places of experience and the detection of body postures in the daily life of the camps: "We believe we know what is terrible.... But we understand nothing. We don't understand the unendingness of hunger. Emptiness. Absence. The body eating itself away. The word 'nothing'. We don't know the camps" (Perec 1992). One must always start again from the: "experience at ground level, what you might call background noise. It's experience grasped at the level of the setting in which your body moves, the gestures it makes, all the ordinariness connected with $[\ldots]$ the exploring of your space" (Perec 1999).

By its nature the field of architecture would seem to be immune to the issues raised so far. Indeed, the nature of the architectural work seems to be the neutral scene of the described equilibria - and tensions - between remembering and forgetting because of a physical presence that remains and, one could say, watches over the community that produced it. More precisely, it could be said that the "neither good nor bad" human faculties of remembering and forgetting, as "they both help deal with life", always save architecture - which is the scenery of life - until a voluntary act of change or physical demolition intervenes. An act that generates nothing more than a new architecture in a continuous cycle. Thus architecture, broadly understood as the organisation of the space built by humanity, contains or rather testifies to a total memory since it is the concrete outcome of every productive act of life. But the areas of investigation mentioned above - "souvenirs dormants", countermonumental strategies and Perec's infra-ordinary perspective - nevertheless lead us to the heart of a crisis of the ongoing role of architecture as a witness of the productive acts of a community, including conflict and violence. The crisis consists in having to reflect on the existence of places - physical or mental - that are completely foreign to the community dimension that would inevitably seem to constitute the foundation of architecture. Places that are radically and desperately unique and solitary even though they are close to a community, places that are unrepresentable even though they are composed of matter and bodies, places whose density appears infinite because every slightest act of forgetting can renew that indescribable "offence" of the "demolition of a man", as Primo Levi described the experience of being held in a concentration camp.

\section{Representing the anonymous}

The experience of political and racial deportation during the Second World War generated a break in the conception of memorial architecture, a paradigm shift that became immediately evident in the post-war recovery. This highlights an element of discontinuity that would have significant consequences on the entire architectural culture of the late $20^{\text {th }}$ century.

The fracture stems from the totally new tasks which memorial architecture was called to perform. First, the task of remembering an act of violence, obviously for the benefit of the victims. This task excludes an entire field of memorial architecture, i.e. commemoration, remembering in a solemn and celebratory form. In fact, here what is being remembered is a loss, but in this case not in the form that memorial architecture typically takes in funeral monuments, aimed at preserving the memory of the life of those who are no longer alive. Indeed, funeral architecture represents a loss but seeks to draw on positive content and can take affirmative tones. The new task, on the other hand, consisted in having to convey the memory of the loss itself, a loss that unites millions of individuals having very different destinies in an identical and shared experience, whose singular personality was erased from life by means of a deliberate project of annihilation. The result is a memorial commitment having a dual paradox.

On the one hand it is necessary to recall an experience of anonymity, of loss of individuality, not the collective experience that the concentration system created, but the 
enormous sum total of singular yet identical coincident experiences of loss, the concurrent loss of personality and sense of every possible community. Because while historical accounts have been able to fix and pass on the collective experience of deportation, by disciplinary statute they are not in the position to recall the profound - common but singular - nature of annihilation, of "an extreme and monstrous attempt to decide between the human and the inhuman, which has ended up dragging the very possibility of the distinction to its ruin", as stated in a consolidated interpretative formula (Agamben 2004, p. 22).

On the other hand we have the second paradox, that the memorial regards the final outcome of a deliberate, violent human action whose purpose was to erase any physical trace of the victim. It is therefore the remembering of a void, the only material trace of which are the physical structures built by the perpetrators to carry out the annihilation. Traces that are increasingly evanescent over time due to natural physical decay, but also due to the fading, or what today we must refer to as the extinguishing, of the direct memory of witnesses who alone can "translate" the sense of the places of Deportation totally determined by the perpetrators - into the language and meanings of those who were their victims.

This memorial task, as paradoxical as it is necessary, has been taken on by literary and artistic languages, but the position of architecture in this regard is specific since architecture not only represents but builds - or reconstructs or destroys - places and does not simply depict or recount experiences but rather allows or generates them. This is evidently not the specific fact of post-war memorial architecture, the element of discontinuity to which reference was made. Architecture as a whole has a dual nature, a dual term of comparison if we refer to the creative processes that guide it: on the one hand the formal conception that manifests itself in representation, on the other hand the material construction that progressively transforms the representation into a physical presence, entrusting the structure to its own unpredictable destiny determined by the passage of time, by circumstance and by active human presence. The breaking point which post-war memorial architecture underscores derives from the different development that the two components - the representation and construction of a place-assume in the face of the memorial task described above.

On the representation front, architecture fully shares its efforts and its difficulties with the other forms of representation and expression - painting, sculpture, writing - that in the second half of the $20^{\text {th }}$ century must deal with the "unmemorable", to use a definition that the aforementioned Agamben has also used in relation to architecture (Agamben 2005). Indeed it can be said that the subject inaugurates a new season of close collaboration between architecture and the arts, characterised by a retreat of architecture with respect to the other forms of expression incorporated within the project with an unprecedented centrality. This is especially true for writing, to which architecture immediately attributes a dual role: on the one hand an instrument for the necessary direct presence of witness accounts, on the other the need for naming as a memorial practice of restoring a brutally stolen identity to the victims. Both forms are ubiquitous, from the "tombstones" that name the victims in the Monument to the Martyrs of the Fosse Ardeatine (competition of January 1944), to the slabs with quotations from the Beatitudes and the tombstones with the names of the deportees added in an update of the project in the Monument to the Fallen in Concentration Camps in Germany by BBPR (Milan, 1945), from the writings taken from the Letters of those in the Resistance condemned to death and from the Hall of Names in the Museum-Monument to Political and Racial Deportees (BBPR, Carpi, 1963) (Leoni 2021), to the centrality of writing in the development process of the Jewish Museum in Berlin (1989) by Daniel Libeskind and the reappearance of the concept in almost all the works in this field. On other fronts, for example the relationship between architecture and sculpture, the disciplinary boundary even tends to disappear, creating a shared form. Consider the whole area of the anti-monument, from the stelae of Jochen Gerz in Hamburg (1986) to the "stumbling stones" of Gunter Demnig, a long-lasting project started in 1992 and still ongoing, just to name a few examples. (Young 1993, 1994, 2000).

With regard to the architectural task and remaining on the representation front, there are basically three strategies for dealing with the paradoxical task of an all-negative memory. The first is an attempt to draw on the tradition of symbolism, both by proposing architectural figures and - this is certainly more interesting - trying to find a form of architectural representation of the impossibility of using symbolic images. The architectural history of this visible impossibility of drawing on the symbol, on the full, positive figure, begins again with the great "tombstone" of the Ardeatine, a real gap in the rich figurative and panoramic narrative of that project, and - after having characterised much of the production on the subject - certainly achieves its expressive and effective acme in the Memorial to the Murdered Jews of Europe (Berlin 1998) by Peter Eisenman.

The second path attempted by architecture consists in setting nature aside before the discipline, which is affirmative, to bring back to the centre of the project, and often limiting it to, an interpretative action of the place. This creates a dialogue with the existing that is always implicit in the act of building a new presence, the final objective of each architectural project, and which, on a case-by-case basis, even beyond the specific topic under discussion and not limited to the historical moment we are dealing with, can become central to a project, typically in restoration projects, but not only. For the memorial architectures dedicated to political and racial deportations during the Second World War, the novel element consists in the duty of this interpretative study of a physical and material nature conducted using architecture to deal with a structure that, as noted above, was totally built by the perpetrator, and which must therefore be opposed in its 


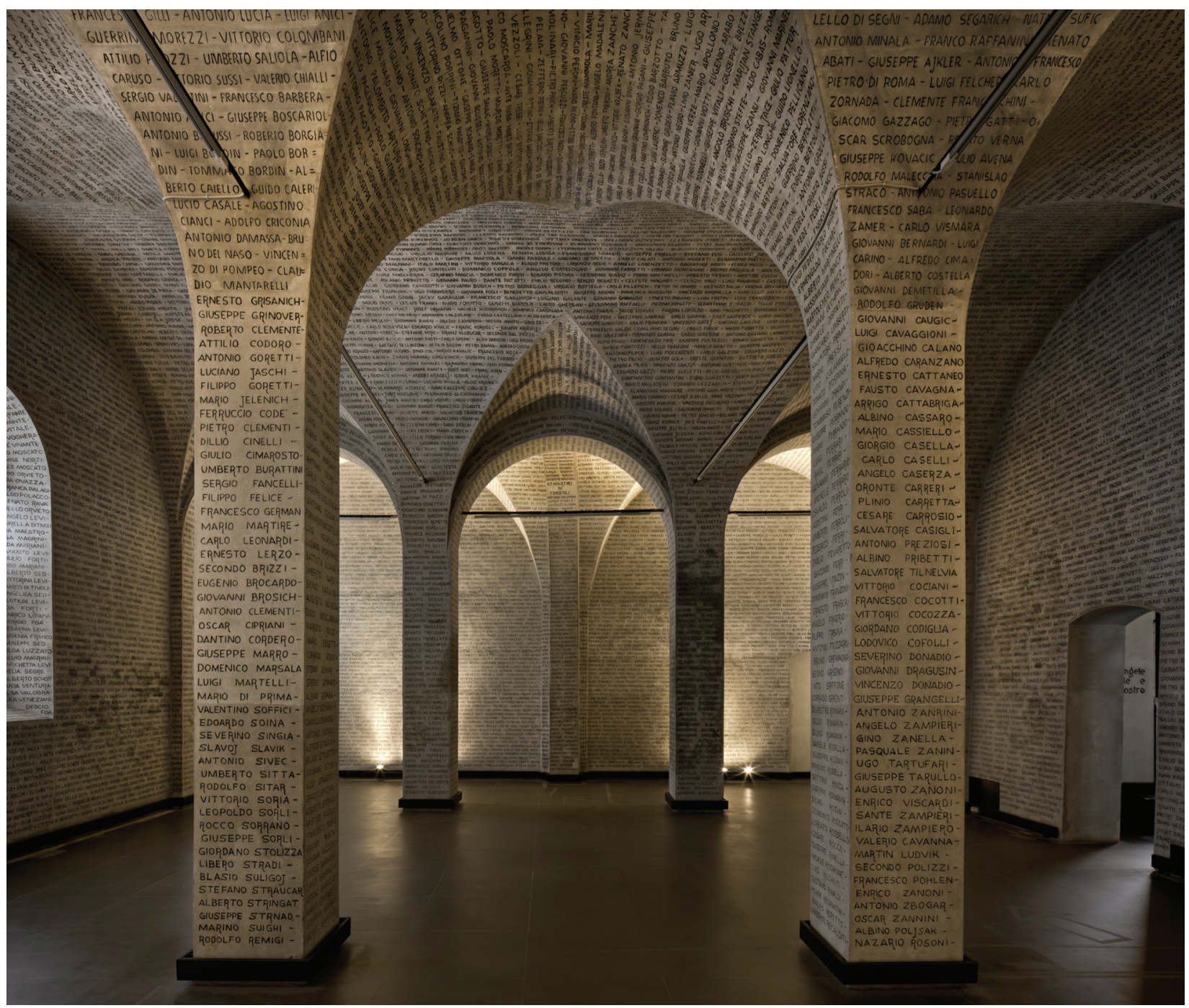

Figure 1. Museo Monumento Carpi.

anonymous nature, having being used primarily for organisational and productive purposes, and which therefore does not manifestly embody the "discourse", the self-representation of the extermination programme, a programme that counts invisibility among its objectives. The space of the perpetrator, simultaneously evident and banal, must be forced, deconstructed and investigated using the tools of architectural design with the aim of conveying and preserving the experience of the victim, free of traces and sedimentation. With an additional difficulty that derives from the inescapable outcome of every architectural project, if that is what it is, namely the appearance of a new presence that, while understood as instrumental to the emergence of the evanescent physical testimony of the victims' past in the place, risks burying them even more deeply under the stratification of evidence and interpretations. While for explicitly symbolic projects the risk - or the field of study - consisted in the not saying and therefore the not understanding of what was stated, here the risk reappears in relation to the reliability and comprehensibility of the "text". In this regard all initiatives to conserve transit, prison and extermination camps deserve an analysis. But it must be emphasised that the interpretative and interrogative nature of the project in some way required by the lieu de mémoire in the strict sense also innervates projects that do not interpret the memorial place but rather build it. This method is fixed in poetic and masterful form in the aforementioned project of the Museum-Monument in Carpi, a work that as is known was designed by a direct witness of the Deportation, but almost invariably reappears in every architecture on the subject, from the central role attributed to the interpretation of the surrounding city in the aforementioned Berlin projects of Libeskind and Eisenman to very recent projects in which the monumental dimension is expressed in an interrogative form such as the Memorial of the Sho$a h$ in Bologna (SET Architects, 2016) or the UK Holocaust Memorial \& Learning Centre (Adjaye Associates and Ron Arad, London, 2021). The disruptive effect of a conception of monumental architecture understood in an interrogative form - somehow a paradox, it has been said - could then be followed throughout the architectural production of the late $20^{\text {th }}$ century, even non-memorial, marking a profound change in sensitivity. 


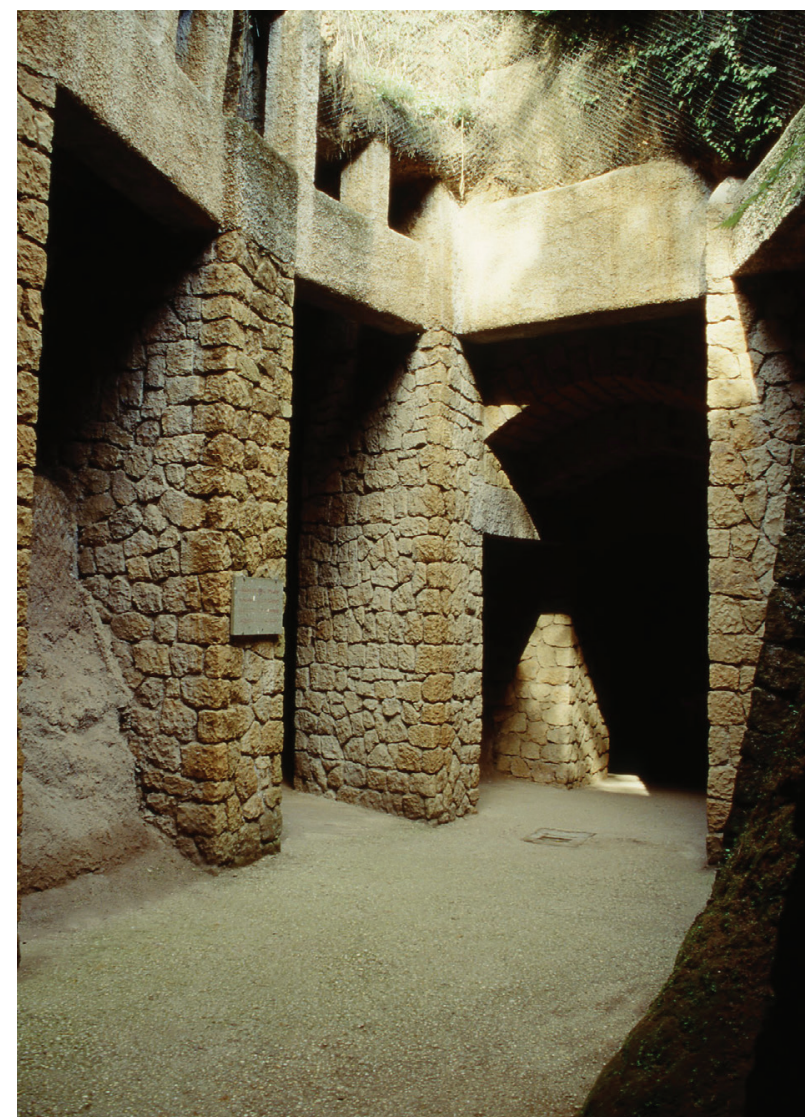

Figure 2. N. Aprile, C. Calcaprina, A. Cardelli, M. Fiorentino, G. Perugini (architecture); Mì Basadella, F. Coccia (sculptures), Fosse Ardeatine Mausoleum, Roma, 1944-1951.

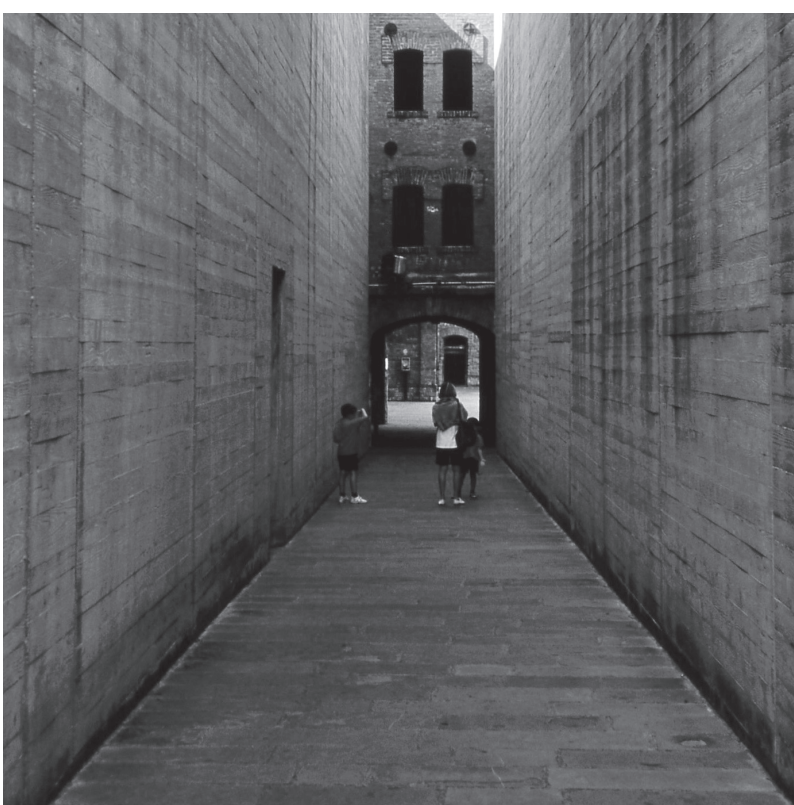

Figure 3. R. Boico, San Sabba Rice Mill National Monument and Museum, Trieste, 1975.

The third path undertaken, while still remaining on the representation front, consists of returning the work of architecture to the pure role of a service space for historical documentary narration or for other forms of narration. Therefore, not the representation of the renunciation of

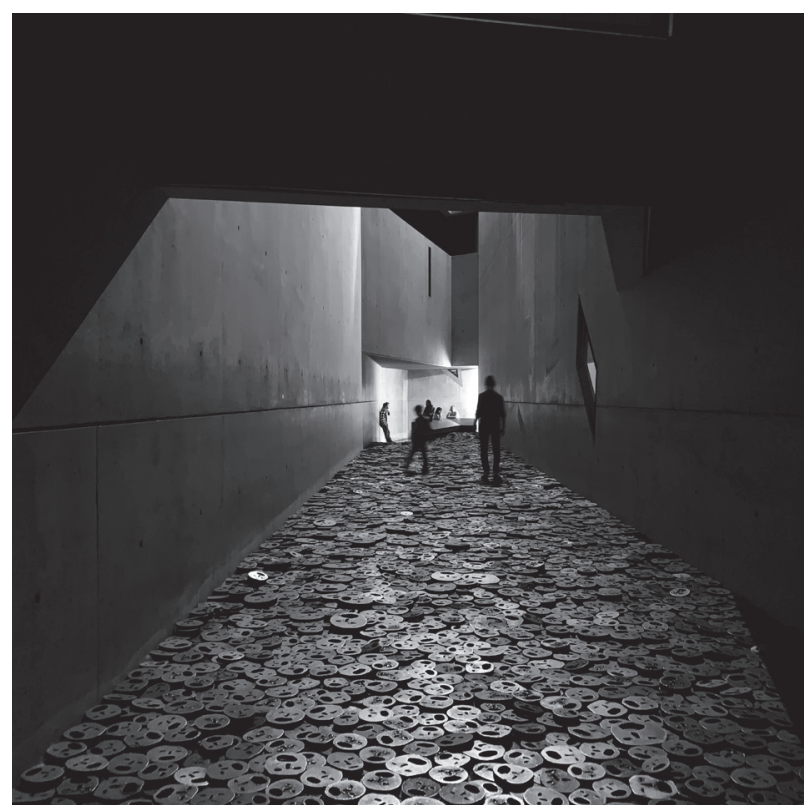

Figure 4. D. Libeskind, The Jawish Museum, Berlin, 1989 2001.

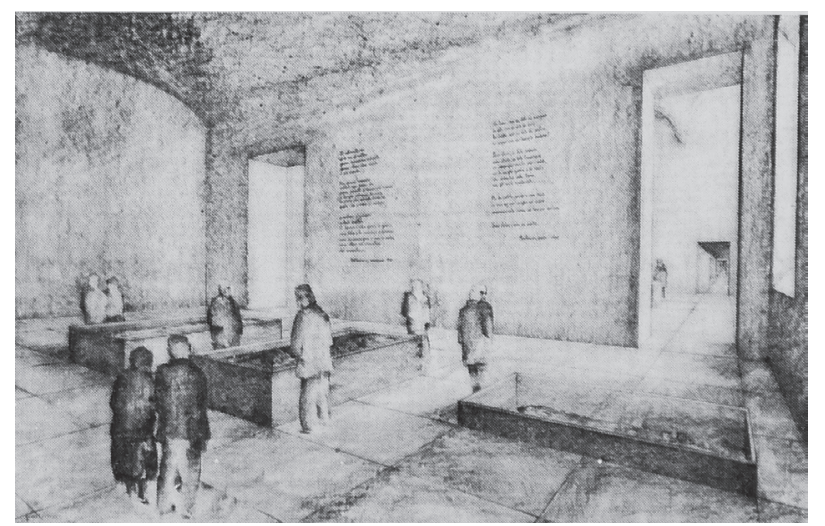

Figure 5. BBPR, Museum-Monument to Political and Racial Deportees in Carpi, drawing submitted for the competition, 1963.

the symbol, not the attempt to find an architectural form to express the unmemorable component and not even the confinement of the architectural language to the role of commenting on the existing, but rather the decision to exempt architecture from any task of representation of memory by offering itself as a neutral medium for other representations or narratives entrusted to other disciplines. An exemplary work in this sense, unfortunately never built after a troubled design process, is the headquarters for the Topography of Terror foundation in Berlin (1993) by Peter Zumthor. Thus we close the circle of the possibilities that architecture has to represent the experience of Deportation, because the renunciation of architecture in service of other expressive forms is the reason for the renewed relationship with the arts and writing mentioned above and that characterises the field throughout the second half of the $20^{\text {th }}$ century.

Of course the three strategies described here are almost never purely expressed in the individual works, and in the 


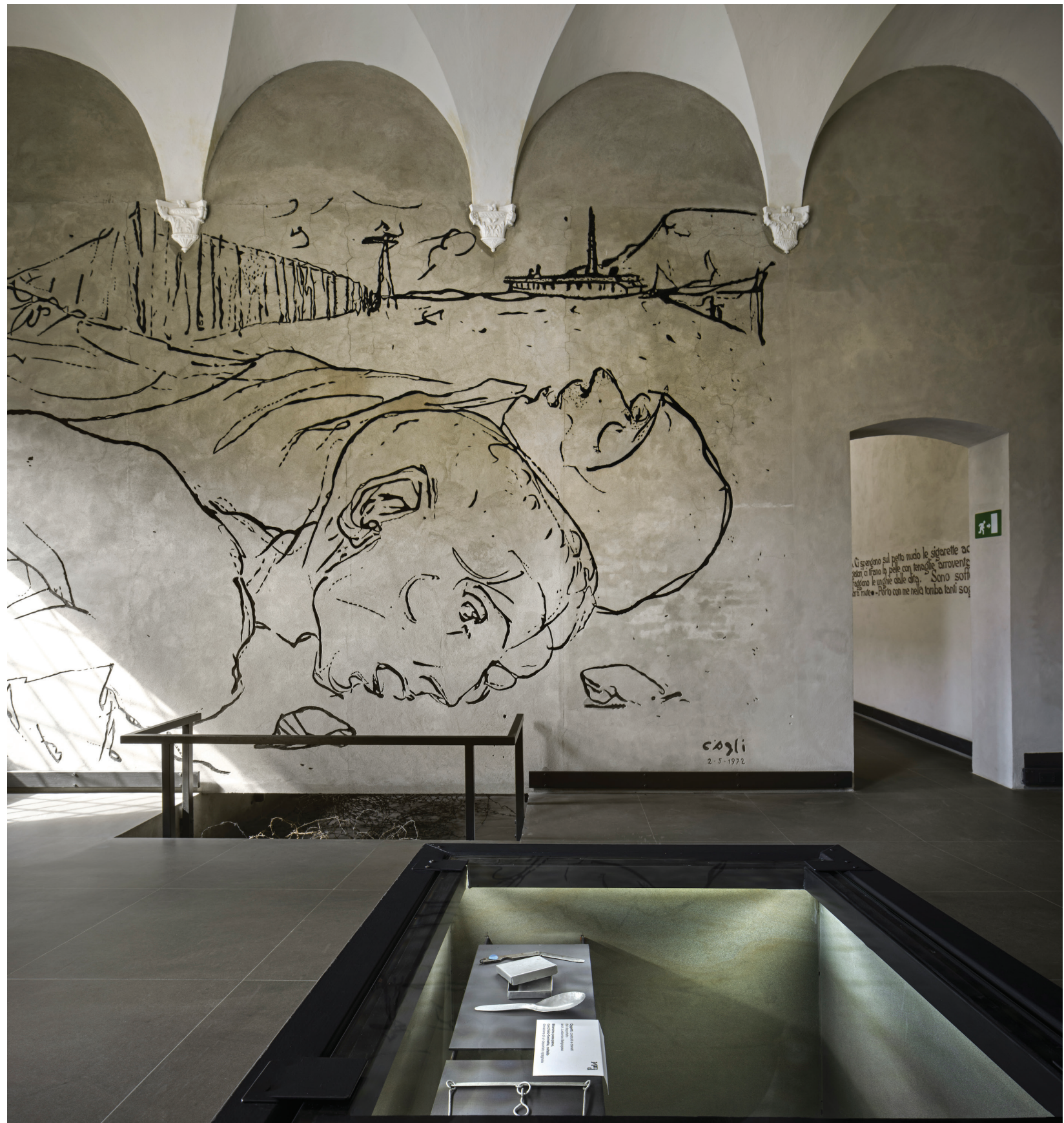

Figure 6. BBPR, Museum-Monument to Political and Racial Deportees, Carpi, 1963-73.

development of the architecture itself symbol, interpretation and act of service mix and often conflict, making the history of most memorial architecture dedicated to Deportation particularly tormented. This happens not only because of the obvious political sensitivity of the area, but also because they are projects that directly deal with a fracture created in the discipline also and above all following the experience they recall, a fracture that the dominant historiography in the field of architecture has mostly neglected in favour of a narrative on the continuity and revision of the Modern Movement, but that in fact radically redefines the tasks of architecture in the second half of the $20^{\text {th }}$ century.

\section{Making visitor's body available to the victims}

It is in the space of this fracture that a specific opportunity of architecture manifests itself, an opportunity linked to its second purpose: not the representation of a form but the construction of an inhabited place. Much more space would be required to precisely exam how in all the works of architecture, in all the spatial devices of the second half of the $20^{\text {th }}$ century dedicated to triggering or supporting memorial processes related to Deportation the subject of crossing, of the movement 
of visitors within space plays a central role. The consideration that BBPR appends to the end of the project report for the competition of the Museum-Monument in Carpi, after having illustrated the complex and innovative memorial device conceived by an architect-witness, as mentioned above, applies to all: "Spectators will practically breathe in the symbolic representation of the events as they travel the winding path of the Castle" (Fossoli Foundation Archive). Here mention must be made of a very broad topic for architecture, namely the definitive crisis of the early $20^{\text {th }}$-century concept of functionalism: for post-war architecture there was no longer any possibility of directing its efforts towards human types, to develop solutions that were standardised or even based on community identities. It is no coincidence that some of the earliest and most enlightened reflections on the crisis of the functionalist model are the considerations on the Anonymous published in Domus magazine by Ernesto N. Rogers during the years that the racial laws were first passed in Italy (Leoni 2017). Architecture is aimed at single persons, all different, to whom it cannot offer a single solution but rather only suggest opportunities for their own individual, singular, non-replicable interpretation of the place. The impact on representation of the desire to control space by geometric means is enormous, with important consequences for the history of architectural languages, but this is not the place to address this topic. But equally important is the opportunity to develop a new conception of architecture that on the one hand establishes an open relationship between the work and the existing surroundings, and on the other brings the body and experience back to the centre of the project. There is no doubt that this new need to set aside early $20^{\text {th }}$-century modernist architecture different in form but in structural continuity with the long cycle of classical styles - in favour of a radically different, interpretative and non-affirmative discipline that understands form as the final outcome and not as a map for the building and development process is decisively driven or even triggered by the paradoxical task described above of interpreting and building places of memorial dialogue with the mass - yet anti-community and totally singular - experience of Deportation. The path through the Ardeatine caves, the view of the naked "wreckage" in the cases of the Museum-Monument in Carpi, meandering among the stelae in the aforementioned projects of Eisenman and Libeskind, walking through the petrified faces, all the same (metal masks, in reality) in the Jewish Museum, the work of the latter and infinite other examples that could be taken from other works show how the subject matter, in its request to deal with annihilated and erased bodies, induces this substitution, requiring visitors to make their own bodies available to the victims and their right to convey and share the violence of the event, a violence that was not healed by the ascertainment of responsibility, which remains over time as an annihilation of humanity and as a threat of a possible repetition of such annihilation.

\section{Conclusion}

Both the recognition of the problems linked to the definition of the relationship between remembering and forgetting in the international debate of the last thirty years and the balance of the challenge and disruption that the experience of political and racial deportation during the Second World War imposed on memorial architecture converge in highlighting the experiential and corporeal dimension of the relationship with the constructions of individual and collective memory. In fact, on the one hand the central point of the tension between remembering and forgetting is claimed as a dynamism of continuity and discontinuity in contrast with the attempt to equivocate the results of neuroscience in favour of a naturalistic neutralisation of the ethical instance of remembrance derived from the history of the $20^{\text {th }}$ century. And this acquisition leads to the possibility of a criticism of memory aids that opens up to experiencing new pathways for the reactivation of dormant memories, countermonumental strategies and uncoded mnestic traces. On the other hand, then, the loss of individuality caused by the experience of the concentration camps and the paradoxical memory of a vacuum that derives from it find a counterpart in the various attempts examined to produce architectures of the unmemorable through multiple strategies that insist on the impossibility of using symbolic images, on putting an interpretation of the places in context at the centre of the project or on bringing the architectural work back to the function of space for the deployment of historical or documentary narration. Criticism of functionalism, openness to anonymity and reassessment of the relationship with the existing surroundings thus converge in putting the body and experience back at the centre of the project. And they converge towards a living experience of what is worthy of being remembered that can only occur through the ability of bodies in action to reactivate latency, tension and experiential triggers that stimulate all senses.

\section{References}

Agamben G (2004) The Open: Man and Animal. Stanford University Press, Stanford; first Italian edition Turin, Einaudi, 2002.

Agamben G (2005) Die zwei Gedächtnisse. Die Zeit, 4 May 2005.

Agamben G (2020) Idea dell'immemorabile. In: Id. (2020) A che punto siamo? Quodlibet, Macerata.

Assmann A (2016) Formen des Vergessens. Wallstein Verlag, Göttingen. Bodei R (1995) Il libro della memoria e della speranza. il Mulino, Bologna: 46-48Cimatti F (2020) La fabbrica del ricordo. il Mulino, Bologna: 157-180.

Didi-Huberman G (2011) Écorces. Minuit, Paris.

Didi-Huberman G (2013) Blancs Soucis. Minuit, Paris. 
Harburger Mahnmal (1994) gegen Faschismus / Jochen Gerz \& Esther Shalev-Gerz, Ostfildern: Hatje. https://kulturtag-harburg.netsamurai.de/harburger-mahnmal-gegen-faschismusLe

Monde (2014) Patrick Modiano, lauréat du prix Nobel de littérature https://www.lemonde.fr/livres/article/2014/10/09/1e-prix-nobel-de-litterature-a-patrick-modiano_4503598_3260.html

Leoni G (2017) Anonymous as a Theme of Discontinuity in the Culture of Italian Architecture between the First and Second halves of the $20^{\text {th }}$ century. In: Progress(es) - Theories and Practices. CRC Press Balkema Taylor and Francis Group, Leiden: 9-13.

Leoni G (2021) In Memory of the Other Resistance: The Places and Architecture of the Fossoli Memorial. In: Cassani Simonetti M, Mira R, Salerno D (Eds) The heritage of a Transit Camp. Fossoli: History, Memory, Aesthetics. Peter Lang, Bern: 107-162. https://doi. org/10.1201/9781351242691-3

Modiano P (2014) Le discours de réception du prix Nobel. Le Monde. https://www.lemonde.fr/prix-nobel/article/2014/12/07/verbatim-le-discours-de-reception-du-prix-nobel-de-patrick-modiano_4536162_1772031.html
Modiano P (2017) Souvenirs dormants. Gallimard, Paris.

Perec G (1992) L. G. Une aventure des annéès soixante. Seuil, Paris.

Perec G (1999) The Work of Memory. In Species of Spaces and Other Pieces. Penguin, London: 127-130.

Pinotti A (2014) L'ultima spiaggia del monumento. Per una tipologia della contro-monumentalità contemporanea. In: L'officina dello sguardo. Scritti in onore di Maria Andaloro, Bordi $\mathrm{G}$ et al (Eds) Gangemi, Rome. https://air.unimi.it/retrieve/ handle/2434/285684/410083/2014.PINOTTI\%20L'ultima\%20 spiaggia\%20del\%20monumento-POSTPRINT.pdf

Reemtsma JPh (2010) Wozu Gedenkstätten?, Aus Politik und Zeitgeschichte, 25/26. https://www.bpb.de/apuz/32663/wozu-gedenkstaetten? $\mathrm{p}=$ all: 3

Young J (1993) The Texture of Memory. Yale University Press, New Haven.

Young J (1994) The Art of Memory: Holocaust Memorials in History. Prestel Verlag, New York.

Young J (2000) At Memory's Edge: After-images of the Holocaust in Contemporary Art and Architecture. Yale University Press, New Haven. 